\title{
VERGONHA: ACRESCENTANDO UM POUCO DE TEMPERO
}

\author{
The Shame: Adding a Little Spice
}

La Vergüenza: Añadir un Poco de Sabor

Artigo Original

\author{
La Honte: En Ajoutant un Peu de Piquant
}

\begin{abstract}
Resumo
O objetivo deste artigo é investigar, à luz do Seminário, livro 17: O avesso da psicanálise, de Jacques Lacan, o estatuto da vergonha na contemporaneidade. O conceito lacaniano de vergonha indica que esse sentimento tem uma relação intrínseca com significante-mestre. Lacan mostra que o sentimento de vergonha está desaparecendo. Essa afirmação nos intrigou e nos fez questionar o que está causando a ausência da vergonha em nossa sociedade. Observamos que houve uma mudança sociedade: o gozo que antes deveria ser encoberto com o véu da vergonha passou a ser escancarado e desavergonhado. Paralelamente, ocorre uma mudança no estatuto do superego, que agora pode ser lido como portador do imperativo de gozo. Mesmo afirmando a ausência da vergonha, Lacan não deixa de apontar que esse é um sentimento importante para a sociedade, bem como para a experiência de análise, pois nos ajuda a lembrar que temos um significante-mestre de onde provém o gozo. Lacan sugere que, durante uma análise, é desejável reconfigurar a vergonha de outra forma.
\end{abstract}

Palavras-chave: vergonha, gozo, significante-mestre, Psicanálise, supereu.

\section{Abstract}

The purpose of this research paper is to investigate in the light of The seminar, Book 17: The Other Side of Psychoanalysis, by Jacques Lacan, the statute of the shame nowadays. The Lacanian concept of shame indicates that this feeling has an intrinsic relationship with the master signifier. Lacan shows that the sense of shame is disappearing. That statement intrigued us and made us to question what is causing the absence of shame in our society. We observed that there was a change society: the enjoyment that, before, should be covered with the veil of shame became blatant and shameless. In parallel, there is a change in the status of the superego, which can now be seen as having the imperative of jouissance. While affirming the absence of shame, Lacan does not fail to point out that this is an important sense for society, as well as for the analytic experience, because it helps us remember that we have a master signifier, hence the jouissance. Lacan suggests that It is desirable to configure the shame of another way, during an analysis.

Keywords: shame, jouissance, master signifier, psychoanalysis, superego.

\section{Resumen}

El objetivo de este artículo es investigar, a la luz del Seminario, libro 17: El reverso del psicoanálisis, de Jacques Lacan, el estado de la vergüenza en la actualidad. Lo concepto lacaniano de vergüenza indica que este sentimiento tiene una relación intrínseca con el significante-amo Lacan muestra que el sentido de la vergüenza está desvaneciendo. Esa

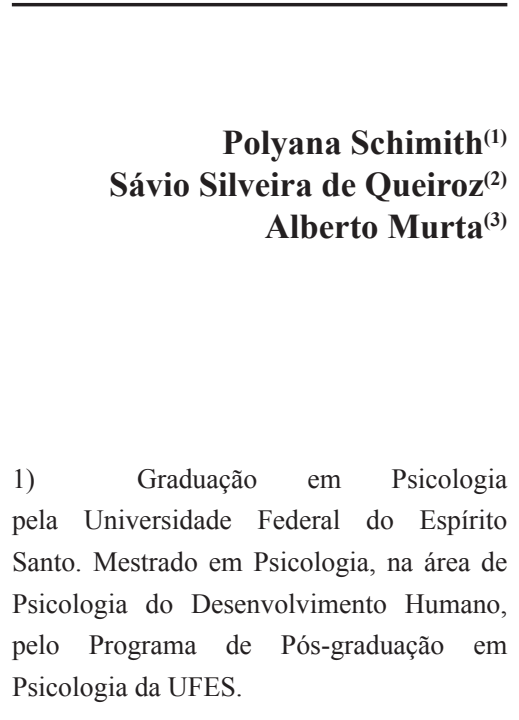

2) Professor Associado no Departamento de Psicologia Social e do Desenvolvimento da UFES e do Programa de Pós-Graduação em Psicologia da UFES.

3) Graduação em Psicologia pela UFES. Mestrado em Filosofia - UFMG. Doutorado em Psicanalise e Campo Freudiano - Université Paris VIII (1996). Pós-doutorado pela UFF. Professor no Departamento de Psicologia na UFES. 
afirmación nos intrigaba y nos hizo cuestionar qué está causando la ausencia de vergüenza en nuestra sociedad. Hemos observado un cambio en la sociedad : el gozo que antes debería ser cubierto con el velo de la vergüenza se convirtió abiertamente y sinvergüenza. Al mismo tiempo, hay un cambio en lo estatuto del superyó, que ahora se puede leer como portador del imperativo gozo. Mismo afirmando la sinvergüenza, Lacan no deja de señalar que este es un sentimiento importante para la sociedad, asi como la experiencia del análisis, porque nos ayuda a recordar que tenemos un significante-amo de donde viene el gozo. Lacan sugiere que este sentimiento debe ser reconfigurado durante el análisis.

Palabras clave: vergüenza, gozo, significante-amo, Psicoanálisis, superyó.

\section{Résumé}

L'objectif de cet article est réaliser une recherche à propos de la honte. Pour faire cette investigation, nous allons nous servir de Jacques Lacan, spécifiquement, Le Séminaire, Livre XVII : l'envers de la psychanalyse. Selon Lacan, la honte faite un rapport intrinsèque avec le signifiant maître. Cependant, la honte se trouve disparaissante dans la contemporanéité. Cette indication lacanienne nous a intrigués et nous a fait nous enquérir ce qui permet l'absence de la honte dans notre société. Ainsi, il y a eu lieu un changement dans la société qui concerne la jouissance. C'est-à-dire, si avant la jouissance était voilée par la honte aujourd'hui, la jouissance se trouve impudence. D'une manière parallèle, il y a aussi un changement qui concerne le statut du surmoi. Le surmoi est devenu l'impératif de la jouissance. Lacan indique que la honte est très importante, soit dans une expérience analytique, soit pour la société. C'est désirable de configurer la honte d'une autre façon, au cours d'une analyse.

Mots-clés: honte, jouissance, signifiant maître, psychanalyse, surmoi.

“Um pouco de vergonha no tempero” (Lacan, 1992, p.

Jacques Lacan (1992) dedica-se, num capítulo do Seminário, Livro 17: O avesso da Psicanálise, a abordar a vergonha, então concebida como um afeto que atesta a presença de um significante-mestre $\left(\mathrm{S}_{1}\right)$. Ele afirma que na sociedade contemporânea a vergonha não existe mais, tendo dado lugar ao seu avesso, nomeado de desvergonha. Este sentimento é produzido por uma sociedade que deve consumi-lo. Então, questionamos: o que está franqueando a ausência da vergonha em nossa sociedade?

Para tentar responder a questão acima, fizemos um retorno à obra de Freud para investigar suas proposições a respeito do estabelecimento da sociedade e das leis que a regem. Além disso, também investigamos algumas nuances e articulações entre as teorias de Freud e Lacan, bem como diferenças entre as sociedades em que cada um estava inserido.

\section{Totem e tabu e o estabelecimentos das leis morais}

Freud (1913/1975a), em seu texto Totem e Tabu, remontou a constituição da civilização por meio da cena do assassinato do pai primevo. Nesse texto, ele sustentou que a partir desse acontecimento, as leis morais foram instituídas. De acordo com esse mito forjado por Freud, após terem assassinado o pai primevo, os filhos entraram em disputas para que apenas um deles ocupasse o lugar que outrora havia sido do pai. Entretanto, logo perceberam que essa luta pelo gozo livre poderia levá-los à própria destruição. A ocorrência desse fato unido ao remorso pelo assassinato do pai levou-os à renúncia daquilo que os impelia a tal ato: o gozo livre. A partir de então, instituíram leis que proibiam o parricídio e o incesto. A respeito do mito freudiano, Lacan (2005, p. 31) afirma o seguinte: "O que Totem e Tabu nos ensina é que o pai proíbe o desejo com eficácia porque está morto". Ou seja: as leis - que antes eram instituídas e mantidas pelo pai - tornaram-se mais fortes depois de seu assassinato, quando surgiu a culpa.

Outra leitura de Lacan (2005) a respeito da concepção freudiano sobre a moralidade revela que ela tem origem na frustração de um gozo. E entende, ainda, que as leis morais eram baseadas em dois pilares: a culpa e a renúncia, cuja origem remonta a relação ambivalente - ódio/amor de filho e pai. Em outro momento, Lacan (2009, p. 166) mostra que Freud trata nesse mito do que posteriormente será a grande inovação de sua segunda tópica: o supereu. A relação entre o mito forjado por Freud e a constituição do supereu é lida por Lacan (2009, p. 166) da seguinte forma:

Qual é a essência do supereu? (...) Qual é a precisão do supereu? Ele se origina precisamente nesse Pai original mais do que místico, nesse apelo como tal ao gozo puro, isto é, à não castração. Com efeito, que diz esse pai no declínio do Édipo? Ele diz o que o supereu diz. (...) O que o supereu diz é: Goza!

Nesse sentido, compreendemos que o supereu se origina daquele pai primitivo, descrito por Freud (1913/1975a) em Totem e tabu, que podia gozar livremente de todas as mulheres e que convoca ao gozo puro. Nesse momento, Lacan entende o gozo puro como a não castração. Nessa nova versão proposta por Lacan (2009), o imperativo do supereu é: goza!

Acompanhando Bastos (2004, p. 251-252), 
compreendemos o gozo como "satisfação pulsional independente do prazer", ou seja, uma satisfação que estabelece-se no mais além do princípio do prazer. Nesse mesmo sentido, podemos ainda recorrer às palavras de Lacan (1992, p. 81):

Eis porque podemos conceber que o prazer seja violado em sua regra e seu princípio, porque ele cede ao desprazer. Não há outra coisa a dizer - não forçosamente à dor, e sim ao desprazer, que não quer dizer outra coisa senão o gozo.

Diante disso, percebemos que esse imperativo estabelecido pelo supereu está na ordem do impossível de satisfazer. Ora, como sabemos, uma satisfação irrestrita da pulsão nos levaria à morte. Lacan (2009, p. 166), alertanos que é aí, nessa impossibilidade de satisfação, "que se elabora o termo consciência moral". Diante da ordem do impossível, não há nenhum modo de prever quais serão os efeitos sobre o sujeito, ou mesmo, sobre a cultura.

\section{Freud e Lacan: leituras de sociedade}

Observamos que Lacan (2005) dá continuidade ao pensamento de Freud apresentando uma nova versão do supereu. Não podemos deixar de notar que as sociedades em que Freud e Lacan produziram as suas teorias foram diferentes. Logo, os sujeitos que faziam parte dessas sociedades também forneciam à clínica psicanalítica materiais diferentes.

Acreditamos que as modificações pelas quais a sociedade passou desde os tempos de Freud até os de Lacan podem ter contribuído para a formulação de uma nova versão do supereu. $\mathrm{Na}$ perspectiva de leitura aberta por Lacan, ele indica uma decadência da vergonha. Por isso, abordaremos dois textos em que os autores investigam a sociedade em que estavam inseridos: o texto freudiano $O$ mal-estar na civilização e o Seminário, livro 17: $O$ avesso da psicanálise, de Lacan. A opção por esses textos foi guiada por Miller (2003, p. 9), pois ele entende que nesse texto Lacan "quis situar o discurso analítico no contexto do momento, então atual, da civilização contemporânea" e ainda "nos deu uma nova edição implícita do Mal-estar na civilização". Comecemos, então, pelo texto freudiano.

No momento em que Freud (1930/1975b) desenvolveu o texto $O$ mal-estar na civilização, a sociedade abordada caracterizava-se por uma maior proibição quando comparada aos dias de hoje. O gozo deveria ser silencioso ou silenciado. O sujeito, que falava a Freud e estava imerso nessa sociedade, tem o supereu em sua estruturação psíquica, como uma instância sempre vigilante e pronta para punilo diante de qualquer ação ou intenção transgressora. Ou seja: não basta apenas que o sujeito renuncie à satisfação pulsional, a presença do desejo de satisfazê-la, por si só, já é motivo para que o supereu entre em ação e o sentimento de culpa se faça presente, acarretando a necessidade de punição. No contexto cultural freudiano, talvez fosse possível afirmar que, ao transgredir uma regra moral, alguém "morresse de vergonha".

Por outro lado, nos tempos de Lacan, o supereu será lido como o responsável por levar o sujeito cada vez mais ao gozo. Em suas próprias palavras: "Aí eu aponto a reserva que implica o campo do direito-ao-gozo. O direito não é o dever. Nada força ninguém a gozar, senão o supereu. $\mathrm{O}$ supereu é o imperativo do gozo - Goza!" (Lacan, 2008a, p.11).

É interessante notar que Lacan (2008a) não destitui o supereu enquanto instância psíquica sempre vigilante, pronto para punir. $\mathrm{O}$ que ele anunciou, já no início dos anos 70, é a "era do direito ao gozo" (Laurent, 2012, p. 1), a era do "É proibido proibir", como Caetano Veloso cantou nesse período. Esse era também o lema do movimento popular que culminou em "Maio de 68". Segundo Eric Laurent (2012), essas “são as duas faces do supereu. Tanto o gozar sem entrave quanto a tolerância zero produzem as duas faces de um mesmo apelo à morte". Portanto, em ambos os momentos históricos - na sociedade que apresentava maior interdição ao gozo e nessa em que assistimos à liberação do gozo - sofremos de certo mal-estar na civilização.

\section{Um pouco de vergonha no tempero}

De acordo com Laia (2009), O Seminário, livro 17: O avesso da psicanálise sofre repercussões diretas do "Maio de 68". Esse momento histórico teve início na França com a manifestação de estudantes e logo tomou o mundo. Nas palavras de Zuenir Ventura (1988, p. 43): "Movida por uma até hoje misteriosa sintonia de inquietação e anseios, a juventude de todo o mundo parecia iniciar uma revolução planetária”. Assim, no momento em que Lacan realizou o seminário, fim de 1969 e início de 1970, estava delineado um cenário mundial de luta por maior liberdade.

Nesse momento de seu ensino, Lacan (1992) abordou a sociedade que lhe foi contemporânea, concomitantemente já fazia o anúncio do que estava por vir. Ou seja: o sucesso na parceria entre o discurso capitalista e o discurso da ciência, que geram como fruto o consumismo (Murta, 2002). Isso se reflete na modalidade de gozo ora em vigência. Já não se satisfaz como antes, atualmente se goza com os objetos de consumo, com os tão em voga gadgets, com as drogas.

Nesse cenário cultural, Lacan (1992, p. 191), na primeira página da lição XIII, afirma: “É preciso dizer, morrer de vergonha é um efeito raramente obtido". A vergonha, nessa perspectiva, configura-se como um afeto que atesta a presença de um significante-mestre e que justificaria para o sujeito o seu próprio existir. É interessante observar, a propósito do $\mathrm{S}_{1}$, que ele formaliza a posição do 
analista a partir do momento em que ele nos lega o discurso do analista, ainda no seminário 17. Podemos constatar que nesse discurso, no lugar da produção, encontra-se o $\mathrm{S}_{1}$. Assim, apresentando o tema da vergonha, ele afirma: "Trouxe-lhes hoje a dimensão vergonha. Não é cômodo falar disso. Não é desta coisa que se fala com facilidade. Talvez seja justamente isso o buraco de onde brota o significantemestre" (p. 200). Apesar de apontar a importância desse afeto, Lacan (1992, p. 193) radicaliza e propõe que "não há mais vergonha". Dessa forma, levanta a hipótese de que a vergonha é o buraco de onde surge o $S_{1}$.

Diante disso, propõe a produção de uma "Hontologie". Este é um neologismo criado por Lacan (1991, p. 209) com base no seguinte jogo de palavras: "honte" (vergonha) e "ontologie" (ontologia). Com esse neologismo sublinha a intrínseca relação entre o sentimento de vergonha e o ser, assim como a sua potência em produzir no ser uma experiência única de existência, pois é o significante-mestre que garante ao sujeito a sua marca singular. A falta desse significante implicaria uma ausência de sentido para a vida, uma tendência para a morte. Essa tendência, todavia, não se transforma em ação, uma vez que a morte encerraria a vergonha; assim, morrer de vergonha fica relegado à ordem do impossível.

Nas palavras de Miller (2003, p. 13): "O desaparecimento da vergonha quer dizer que o sujeito cessa de ser representado por um significante que valha". Logo, o que resta ao sujeito é uma vergonha de viver. Ao afirmar a ausência da vergonha, Lacan (1992) indica uma denegação do significante-mestre, a qual começou a se instalar desde o final dos anos 60 e início dos anos 70 do século passado. Nesse mesmo período começa a ascensão do direito ao gozo.

A proposição lacaniana sobre o desaparecimento da vergonha é lida por Miller (2003) como fruto de um eclipse do olhar do Outro, como portador de vergonha. Sendo que o aqui é considerado como objeto $a$. Lacan (2008b), em seu Seminário, livro 11: os quatro conceitos fundamentais da psicanálise, serve-se de uma passagem de Sartre (1943/1997) para explicar as relações entre o olhar, enquanto objeto, e o sentimento de vergonha. O filósofo, na obra o Ser e o Nada, relata uma situação em que o sujeito está olhando pelo buraco de uma fechadura quando ouve passos; nesse mesmo instante tem a sensação de ser olhado por alguém. Assim, sujeito que olha uma cena proibida pelo buraco da fechadura vai se tornando o olhar escondido, ou seja, o sujeito se reduz ao objeto $a$.

Miller (2003, p. 10) mostra que, na história de Sartre, encontramos dois momentos: no primeiro, o que o sujeito olha pelo buraco da fechadura; no segundo, quando escuta passos no corredor e já sente vergonha. Antes mesmo que o rosto daquele que o olha esteja presente, o personagem já formula: "alguém me olha". É um olhar anônimo, atrás do qual se esconde o olhar do Outro. Podemos entender que é daí que surge a vergonha: o sujeito se declina ao estatuto de objeto $a$. Ou seja: ele se torna objeto da própria pulsão.

Acompanhando Lacan (1992) numa outra aula do Seminário, livro 17 , podemos isolar uma passagem que presentifica algo do eclipse do olhar do Outro. É a passagem em que ele se endereça aos estudantes de Vincennes dizendo: vocês "desempenham a função de hilotas desse regime. Vocês também não sabem o que isso quer dizer? Ele diz - Vejam como gozam" (p. 218).

A relação entre o olhar e o supereu era apontada por Freud (1975c, p. 99) ainda em 1923: "[o ego] é observado a cada passo pelo supereu severo". Porém, para ele, a vigilância do supereu tinha função de velar o gozo. Lacan (1992, p. 218), como pudemos verificar anteriormente, anuncia que o olhar, que antes velava o gozo, está perdendo essa função. Desse modo, o olhar já não causa mais vergonha; ao contrário, o supereu se torna esse imperativo de satisfação: "vejam como gozam" e gozem. Dito de outro modo, o olhar do Outro, castrado de sua potência de produzir vergonha, demonstra a outra face do supereu. Essa outra face se encontra presente na nossa atualidade e se traduz pelo seguinte imperativo do gozo: "olhem eles gozarem e gozem também” (Miller, 2003, p. 12).

Nessa época do direito ao gozo, os sujeitos que gozam parecem mais normais. Isso se torna evidente quando observamos a alta audiência e a proliferação de reality show na programação televisiva. Miller (2003, p. 11) argumenta: "É como se essa apreensão do espetáculo televisual tivesse como missão, em todo caso como consequência inconsciente, demonstrar que a vergonha está morta”.

A Psicanálise tem chamado a atenção para um regime de produção e consumo no qual estamos inseridos. Nesse contexto, até mesmo o sentimento de vergonha é produzido e deve ser consumido. Lacan (1992, p. 202) mostra que essa produção de vergonha se traduz pela "desvergonha". Isto é: nos tempos da ausência da vergonha, o que resta é essa desvergonha que compartilha o gozo ao invés de velá-lo. Esse compartilhamento acontece, de maneira explícita, nas redes sociais. Um mundo virtual onde tudo é publicado e, simultaneamente, compartilhado; onde os mínimos detalhes da vida cotidiana são transformados em espetáculos que a todo o momento convocam o olhar.

Portanto, a desvergonha (Lacan, 1992, p. 202) é um sentimento que a sociedade produziu e deve ser consumido, mas não provoca nenhum tipo de impedimento. Dito de outro modo, o consumo desse sentimento não impede o sujeito de cometer atos imorais, ao contrário, impele o sujeito a tais atos. Nesse contexto de produção e consumo, a Psicanálise lacaniana denuncia um discurso quantitativo que tenta anular o sujeito do desejo e substituí-lo pela figura de um consumidor passivo, em que o próprio sujeito se torna uma cifra. Miller (2009, p. 6) ressalta: "Ser, hoje, é ser cifrado, é ser contável e contado". Desse modo, somos apenas mais um ponto no Ibope, um percentual no censo, 
nas estatísticas. Enfim, estamos falando de uma lógica mercantil que promove a apropriação econômica do sujeito. Como consequência, o sujeito perde a sua singularidade, perde a sua honra. Miller (2003, p. 14) nos esclarece: “A honra da Psicanálise decorre do laço mantido do sujeito com o significante-mestre".

Até este momento, abordamos a perspectiva da psicanálise acerca das mudanças culturais. Agora, faz-se necessário questionar qual o posicionamento da clínica psicanalítica diante dessas mudanças culturais. Para tanto, vamos abordar dois casos clínicos: o caso de Vatel - por meio do qual Lacan demonstra que já foi possível morrer de vergonha; e o relato de final de análise de Guy Briole, que testemunha o atravessamento da vergonha.

\section{O tempero na prática clínica}

Lacan (1992, p. 204) encerra o Seminário, livro 17: $O$ avesso da psicanálise com as seguintes palavras: "não demasiado, mas o suficiente, me acontece provocar-lhes vergonha". Eventualmente, o lugar ocupado pelo analista no seu discurso passa pelo objeto $a$ enquanto causa. $\mathrm{O}$ analista, agenciando o outro, causa o outro, na ocorrência, o sujeito barrado. Um dos efeitos dessa causação, é a produção de $\mathrm{S}_{1}$. Diante disso, Laurent (2002, p. 5) indaga se é função do psicanalista provocar vergonha. No entanto, o que é essa posição de causar vergonha? Comecemos por dizer o que não é: a posição de causar vergonha não se assimila à de causar culpa.

Ao dedicarmo-nos a teoria de Freud (1913/1975a), observamos que o sentimento de culpa era muito importante para o estabelecimento e para a manutenção de leis morais. Não é possível afirmar que a vergonha tenha essa mesma atuação, porém, por sua relação com o objeto olhar, ela pode impedir que o gozo seja escancarado, aspecto típico da sociedade atual. Além disso, de acordo com Franco (2007), a vergonha pode ser diferenciada da culpa por ter uma relação com o $\mathrm{S}_{1}$, isso quer dizer que a vergonha é um sentimento mais íntimo do sujeito. A culpa também tem uma relação com o olhar do Outro, mas com um Outro que julga as ações do sujeito.

Aaçãopsicanalítica se orientapelanão desculpabilização do sujeito (Franco, 2007). Ou seja, uma vez que o sujeito se declare culpado, não é função do psicanalista negar-lhe a culpa, porque o sujeito, ao se des-culpar, retira a sua culpa e pode retirar também a sua responsabilidade (Laurent, 2002). Quanto a isso, Lacan (1998, p. 873) não poderia ser mais contundente: "Por nossa posição de sujeito, sempre somos responsáveis". A concessão de perdão, pela via contrária, promove o esquecimento da honra e, por conseguinte, da vergonha. Não estamos dizendo que cabe ao psicanalista promover a culpabilização do psicanalisando. Estamos dizendo apenas que o psicanalista não deve ocupar um lugar daquele que concede perdão. Não é disso que trata a posição de causar vergonha. Provocar vergonha, de modo algum, supõe perdão (Miller, 2003). Então, o que é essa posição de provocar vergonha? Eric Laurent $(2002$, p. 7) nos fornece uma possível resposta:

(...) a posição de "causar vergonha" não consiste em fixar mas em dissociar o sujeito do significante-mestre e, por aí, a fazer perceber o gozo que o sujeito tira do significantemestre. Lá onde o mestre mostra, e mostra sem pudor, a obscenidade, o psicanalista, ao contrário, recoloca o véu e evoca esse demônio sob a forma de vergonha.

Entretanto, essa posição de causar vergonha pode ser bastante perigosa. Freud (1905/1975d), no texto Três ensaios sobre a teoria da sexualidade, já anunciava que a vergonha em excesso poderia trazer malefícios. Lacan (1992), por sua vez, expõe o exemplo de um homem que morreu de vergonha.

Antes de abordar esse caso, gostaríamos de sinalizar que não estamos falando aqui de pudor. Esse tema foi abordado por nós em outro estudo (Murta e Schimith, 2012), no qual observamos que, no último momento de seu ensino, Lacan (2007) revela que o pudor é um dos últimos semblantes a serem sacudidos no final de uma análise, mas, de forma alguma, transgredido. Derrubar a barreira do pudor faz com que o gozo seja exibido e valorizado, e, assim, a saída de análise se daria pela via da perversão.

Retomando o exemplo relatado por Lacan (1992), François Vatel. Este foi um maître d'hôtel que se tornou famoso por promover eventos e festas com grande esplendor. No ano de 1671, ele foi imbuído da grandiosa tarefa de promover três dias e três noites de festa para receber toda a corte. Tudo correu bem até o jantar da última noite; para o qual ele havia planejado servir peixes e frutos do mar, mas esses produtos não foram entregues a tempo. Ao ver que a recepção preparada por ele fracassaria, Vatel comete suicídio. O Rei Luís XIV e toda a sua corte ficaram admirados com a sua atitude e sua morte tornou-se uma tragédia nacional.

Para Lacan (1992), esse homem, por sua fixação com seu significante-mestre, "morreu de vergonha". O S confere ao sujeito a sua singularidade, é o que marca com aquilo que lhe é próprio; portanto, ao abrir mão dele, o sujeito perde a sua capacidade de sentir vergonha. Por outro lado, permanecer fixado a ele, pode levar o sujeito à morte, como no caso de Vatel. Ora, se a vergonha levou Vatel à morte, então, por que o psicanalista precisa causar vergonha?

De acordo com Miller (2003, p 38), "na operação analítica trata-se, sem dúvida, de separar o sujeito de seu significante-mestre. Mas, isso supõe que ele saiba que tem um e o respeite". Essa separação se faz necessária porque permite que o sujeito perceba o gozo que tira daí. Lacan (2008a, p. 30), no Seminário, livro 20: mais, ainda, é claro 
ao apontar que o gozo é causado pelo significante. Em suas palavras: "O Significante é a causa do gozo". Isso posto, se assumirmos a perspectiva lacaniana de que o $S_{1}$ brota do buraco da vergonha, podemos compreender que provocar vergonha pode fazer brotar o $\mathrm{S}_{1}$ de onde sujeito tira seu gozo. Por conseguinte, quando Lacan sugere esse provocar vergonha, não é para cultivá-la, mas sim, para trazer à tona a relação do sujeito com seu significante-mestre (Alberti, 2009). Nesse sentido, sugerir que o analisando seja afetado pela vergonha na experiência de análise é apenas pôr um temperinho a mais nessa experiência.

Diante disso, abordaremos, de agora em diante, o testemunho de final de análise de Guy Briole (2011). Pela operação analítica, tornou-se possível o deslocamento de seu significante-mestre e, por conseguinte, ele ultrapassou a vergonha.

Entre os significantes que surgem em sua análise, podemos destacar aquele que dá nome ao seu relato: a cicatriz. Ele era marcado por algumas cicatrizes: a circuncisão; a detenção do pai pela Gestapo; a "doença" da mãe... Todas elas causavam a vergonha. Esse afeto emergia especialmente quando algum olhar era lançado à cicatriz de sua circuncisão. Quanto ao surgimento da vergonha, ele relata a seguinte cena, que ocorreu no momento em que o curativo da circuncisão era refeito: "Minha mãe estava presente, ela olhava, e esse olhar era-me insuportável; ele fixou a marca e me fez surgir a vergonha" (Briole, 2011, p. 156).

Observamos, no trecho acima, a intrínseca relação entre o olhar e o surgimento do sentimento de vergonha. Em suas relações sexuais, Briole (2011) escondia a sua marca de sua circuncisão do olhar das mulheres. Ao fim de cada ato sexual, ele realizava um ritual conferindo se a "cicatriz não tinha sido reavivada" (p. 157).

De acordo com o relato de Briole (2011), o atravessamento da experiência de análise possibilitou que ele descolasse de seu objeto e, por consequência, abandonasse a sua posição de gozo. Dois sonhos são relatados e interpretados por ele como sua separação de uma casca que o cobria inteiro. Em suas palavras: "Eu deixei a casca, o prepúcio! Eu me cobria inteiro com esta casca. Eu me separei dela" (p. 158). A partir de então, ele "estava nu, sem casca". Briole (2011, p. 158) anuncia que doravante "não é mais o olhar que está em jogo". Ou seja: ele realiza uma nova leitura das próprias marcas: o corpo, que antes o envergonhava, agora se torna um "belo corpo" (p. 158). Ao se descolar do objeto de onde tirava seu gozo, Guy Briole ultrapassa a vergonha.

Diante da experiência relatada por Briole (2011), podemos entender que Lacan (1992) não propõe uma manutenção do sentimento de vergonha, pois esse pode causar a fixação do sujeito ao $\mathrm{S}_{1}$. De maneira contrária, ele propõe que a vergonha seja experimentada, para em seguida ser reconfigurada.

\section{Considerações Finais}

Em face do que tentamos desenvolver logo acima, podemos constatar que Lacan (1992) sinaliza a ausência da vergonha. Dessa maneira, o questionamos do estatuto da vergonha se torna crucial na atualidade. Parece-nos que esse fenômeno vem ocorrendo paralelamente à mudança de estatuto do supereu: se nos tempos de Freud ele impedia o gozo, hoje ele o escancara. Diante disso, Lacan (1992) sugere ao psicanalista um "provocar vergonha" (p. 204) ou "um pouco de vergonha no tempero" (p. 191). No entanto, não podemos perder de vista que tanto o excesso quanto a ausência absoluta podem ser lidos como faces de um supereu que tem como imperativo o gozo. Assim, o que a psicanálise propõe é uma via que siga no meio termo entre o gozo desenfreado e a interdição absoluta.

\section{Referências}

Alberti, C. (2009). Afetos. In Scillicet - Semblantes e Sinthoma (pp. 33-35). São Paulo: Escola Brasileira de Psicanálise.

Bastos, A. (2004). Segregação, gozo e sintoma. Revista mal-estar e subjetividade, 4(2), 25-265.

Briole, G. (2011). Essa cicatriz, aqui. Opção Lacaniana Revista Brasileira Internacional de Psicanálise, 61, 155-160.

Franco, I. F. (2007). Realidade social: a violência, a segregação e a falta de vergonha. Revista Mal-estar e Subjetividade, 7(2), 269-284.

Freud. S. (1975a). Totem e Tabu. In J. Strachey (Org.), Edição Standard das Obras Psicológicas Completas de Sigmund Freud (Vol. XIII, pp. 13-193). Rio de Janeiro: Imago. (Obra original publicada em 1913).

Freud. S. (1975b). O Mal-estar na civilização. In J. Strachey (Org.), Edição Standard das Obras Psicológicas Completas de Sigmund Freud (Vol. XXI, pp. 71-171). Rio de Janeiro: Imago. (Obra original publicada em 1930).

Freud. S. (1975c). O Ego e o id. In J. Strachey (Org.), Edição Standard das Obras Psicológicas Completas de Sigmund Freud (Vol. XIX, pp. 13-83). Rio de Janeiro: Imago. (Obra original publicada em 1923).

Freud. S. (1975d). Os três ensaios sobre a sexualidade. In J. Strachey (Org.), Edição Standard das Obras 
Psicológicas Completas de Sigmund Freud (Vol. VII, 123-252). Rio de Janeiro: Imago. (Obra original publicada em 1905).

Lacan, J. (1991). Livre XVII: L'envers de la psychanalise. Paris: Seuil.

Lacan, J. (1992). Seminário, livro 17: O avesso da psicanálise. Rio de Janeiro: Zahar.

Lacan, J. (1998). A ciência e a verdade. In J. Lacan. Escritos (pp. 869-892). Rio de Janeiro: Zahar.

Lacan, J. (2005). O triunfo de religião, precedido de, Discurso aos católicos. Rio de Janeiro: Zahar.

Lacan, J. (2007). O Seminário, Livro 23: o sinthoma. Rio de Janeiro: Zahar.

Lacan, J. (2008a). Seminário, livro 20: mais, ainda. Rio de Janeiro: Zahar.

Lacan, J. (2008b). Seminário, livro 11: os quatro conceitos fundamentais da psicanálise. Rio de Janeiro: Zahar.

Lacan, J. (2009). Seminário, livro 18: um discurso que não seria de semblante. Rio de Janeiro: Zahar.

Laia, S. (2009). Análise e interpretação de uma efusão coletiva: os discursos, a ação lacaniana a partir de maio de 68 e suas consequências. Revista Curinga, 13, 97 11.

Laurent, É. (2002). A vergonha e o ódio de si. Carta de São Paulo, 2-11.

Laurent, É. (2012). O tratamento das escolhas forçadas da pulsão. [Entrevista concedida à Fernanda Otoni]. Responsabilidades, 2(1), 21-31.

Miller. J.-A. (2003). Nota sobre a honra e a vergonha. Opção Lacaniana - Revista Brasileira Internacional de Psicanálise, 38, 8-18.

Miller, J.-A. (2009). Qual a política lacaniana para 2009? Opção Lacaniana - Revista Brasileira Internacional de Psicanálise, 53, 3-8.

Murta, A. (2002). Do sujeito ao Falasser. Sofia, 8 (9), 13-25.

Murta, A, \& Schimith, P. (2012). De qual pudor falamos em análise? Opção Lacaniana Online, 3(9), 1-10.

Sartre, J.-P. (1997). O ser e o nada - Ensaio de ontologia fenomenológica. Petrópolis: Vozes. (Trabalho original publicado em 1943).

Ventura, Z. (1988). 1968: O ano que não terminou. Rio de Janeiro: Nova Fronteira.

\section{Endereço para correspondência:}

Polyana Schimith

Endereço: Rua Diná Feu Ribeiro, no 34/111, Ed. Coimbra, Mata da Praia. Vitória/ES. CEP: 29065-710

E-mail: ninha.bs@gmail.com

\section{Endereço para correspondência:}

Sávio Silveira de Queiroz

Endereço: Rodovia ES 010, km 6,5, Condomínio

Arquipélago de Manguinhos. Serra/ES. CEP 29173-087

E-mail: savio.queiroz@ufes.br

\section{Endereço para correspondência:}

Alberto Murta

Endereço: Rua Mary Ubirajara, n 40/102, Santa Lúcia.

Vitória/ES. CEP: 29056-030

E-mail: bmurta@terra.com.br 